\title{
MEDICINE
}

\section{РОЛЬ КЕТОЗА ПРИ АЛКОГОЛЬНОЙ ЗАВИСИМОСТИ И ЭФФЕКТИВНОСТЬ ПРЕПАРАТОВ ПРИ УСТРАНЕНИИ АЛКОГОЛИЗМА}

\author{
к.б.н. Э. С. Багдасарова, \\ к.б.н. В. Б. Расулова,
}

Узбекистан. Ташкент. Ташкентский фармацевтический институт

DOI: https://doi.org/10.31435/rsglobal_wos/31012019/6311

\section{ARTICLE INFO}

Received: 07 November 2018

Accepted: 10 January 2019

Published: 31 January 2019

\section{KEYWORDS}

ketosis,

alcoholism,

atsetoaldegidrogenaza,

hypoglycemia,

ketonic bodies,

glucose of blood,

Zoreks,

Teturamum.

\begin{abstract}
Alcoholism is the problem disturbing all international community. Elimination of this problem will give the chance to keep life of millions of people and to make their life more fruitful. For elimination of alcoholism first of all it is necessary to find out inclinations to it. The experiments made earlier showed that despite the expressed hypoglycemia, alcohol dependent rats refuse the glucose use. It occurs because the brain passed to food with other substrate - ketonic bodies which are ethanol metabolites in an organism. It follows from this that ethanol metabolites (ketonic bodies) become the only energy source for a brain. As a result ketonic bodies begin will be excreted with urine and there is a ketosis. I aim our experiment clarification of the mechanism of alcohol addiction and finding of more effective remedy from alcoholism by comparison of two drugs is: Zoreks and Teturamum.
\end{abstract}

Citation: Э. С. Багдасарова, В. Б. Расулова. (2019) Rol' Ketoza pri Alkogol'noj Zavisimosti i Ehffektivnost' Preparatov pri Ustranenii Alkogolizma. International Academy Journal Web of Scholar. 1(31), Vol.1. doi: 10.31435/rsglobal_wos/31012019/6311

Copyright: (C) 2019 Э. С. Багдасарова, В. Б. Расулова. This is an open-access article distributed under the terms of the Creative Commons Attribution License (CC BY). The use, distribution or reproduction in other forums is permitted, provided the original author(s) or licensor are credited and that the original publication in this journal is cited, in accordance with accepted academic practice. No use, distribution or reproduction is permitted which does not comply with these terms.

Введение. Алкоголизм является проблемой, тревожащей все мировое сообщество. Устранение этой проблемы даст возможность сохранить жизни миллионов людей и сделать их жизнь более плодотворной. Для устранения алкоголизма прежде всего необходимо выяснить механизм влечения к нему. Одна из наиболее актуальных в физико-химическом аспекте

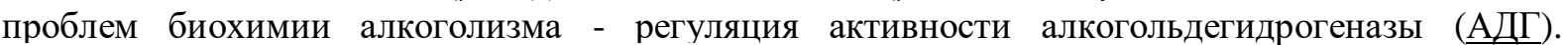
Действующее начало в любом алкогольном напитке - этанол [5;6].

Проводимые ранее опыты показывали, что, несмотря на выраженную гипогликемию, алкогользависимые крысы отказываются от употребления глюкозы. Это происходит потому, что мозг перешел на питание другим субстратом -кетоновыми телами, которые являются метаболитами этанола в организме. Из этого следует, что единственным источником энергии для мозга становятся метаболиты этанола (кетоновые тела). В результате кетоновые тела начинают выделятся мочой и возникает кетоз. Кетоз - естественное состояние организма, когда кетоновые тела (далее кетоны) становятся основным источником энергии.

Гипогликемические эффекты алкоголя могут представлять потенциальную опасность.

Алкоголь влияет на различные аспекты метаболизма глюкозы. В частности, было показано, что алкоголь ингибирует на $45 \%$ глюконеогенез, что может быть опосредовано нарушением редокс-потенциала, дозозависимым стимулированием выброса адреналина и 
норадреналина и т. д [1]. Алкоголь также может усиливать гипогликемические эффекты других препаратов (например, бетта-блокаторов) [1].

Зависимость от этанола можно объяснить на примере следующего порочного круга [3]:

употребление этанола $\rightarrow$ гипогликемия $\rightarrow$ образование кетонов $\rightarrow$ питание мозга кетонами потребность в кетонах $\rightarrow$ потребность в алкоголе $\rightarrow$ употребление этанола. Исходя из этой схемы стало ясно, что для устранения алкоголизма прежде всего необходимо ограничить доступ к этанолу с помощью препаратов, а затем обратно перестроить мозг на питание глюкозой.

Целью нашего эксперимента является выяснение механизма алкогольной зависимости и нахождение более эффективного средства от алкоголизма путем сравнения двух препаратов: Зорекса и Тетурама.

Для выяснения более точного механизма действия в первую очередь обратимся к химической структуре главных действующих веществ в составе препаратов, а именно унитиола (Зорекс) и дисульфирама (Тетурам).<smiles>O=S(=O)(CC(S)CS)O[Na]</smiles>

унитиол<smiles>CCN(CC)C(=S)SSC(=S)N(CC)CC</smiles>

дисульфирам

Puc. 1.

Зорекс. Фармакологическое действие Зорекса заключается в способности его связывать токсичные метаболиты этанола (ацетальдегид), с помощью сульфгидрильных групп. Ацетальдегид образуется из этанола путем дегидрирования и вызывает следующие симптомы похмелья как тошнота, тахикардия, гипотензия и др.

Тетурам. Ингибируя фермент ацетоальдегидрогеназу, Тетурам способствует накоплению токсичного ацетальдегида в крови после приема алкоголя, что приводит к очень неприятным ощущениям и способствует выработке отрицательного рефлекса на вкус и запах спиртных напитков. Тетурам блокирует альдегиддегидрогеназу, которая переводит ацетальдегид в воду и углекислоту. В результате после приема этанола на фоне тетурама происходит накопление ацетальдегида. Физиологическая концентрация ацетальдегида нейтрализуется путем естественных метаболических реакций, так как он является метаболитом нейронов мозга. При отравлении тетурамом или совместном с ним приемом этанола образуется повышенная концентрация этого альдегида, который становится токсическим веществом, нарушающим функцию центральной и периферической нервных систем, сердечно-сосудистой системы, вызывая тяжелое состояние больного. Это используют для выработки условного рефлекса, с помощью которого и происходит отвыкание от употребления алкоголя [2].

Методы и материалы исследования. Эксперимент выполняется на 36 крысах обоих полов, доступ к пище свободен. В течение 16 недель крысы подвергались принудительной алкоголизации $10 \%$ этанолом. После окончания алкоголизации у животных был свободный выбор между водой и 10\% этанолом. При этом крыс разделили на 6 групп и в течение 3 недель 2 раза в день вводили следующие препараты:

1. С целью устранения кетоза животным первой группы вводили 0,5 мл 1,4\% p-p Зорекса $(3,5 \mathrm{Mr} / к г)$

2. С целью устранения гипогликемии животным второй группы вводили 0,5 мл $20 \%$ p-p глюкозы $(0,5$ г кг $)$

3. Животным 3 группы с целью устранения и кетоза и гипогликемии вводили 0,5 мл смеси: 0,25 мл 2,8\% Зорекса и 0,25 мл $40 \%$ глюкозы

4. Животным четвертой контрольной группы вводили 0,5 мл $0,9 \%$ раствор хлорида натрия

5. Крысам 5 группы вводили 0,5 мл 1,4 \% р-р Тетурама

6. Животным 6 группы была введена смесь, состоящая из 0,25 мл 2,8\% Тетурама и 0,25 мл глюкозы.

Поскольку животные значительно различались между собой в весе, делали перерасчет объема выпитого спирта в миллилитрах на 100 гр масс тела крысы. Мониторировали содержание глюкозы в крови и кетоновых тел в моче. Забор проб жидкостей проводили с утра до перорального введения. Забор 0,5 мл крови проводили из хвостовой вены. Сбор мочи производили, высаживая крысу в пластиковый контейнер с перфорированным дном. Моча стекала в поддон. Для анализа мочи был использован MINDRAY UA-66. При этом специальная 
тест -полоска была пропитана мочой и по интенсивности краски прибор автоматически определял концентрацию кетоновых тел. Количество глюкозы в крови был определен на приборе HUMALYZER PRIMUS Human.

Результаты исследования. У здоровых крыс, участвующих в эксперименте, кетоновых тел не обнаружено. Уровень глюкозы у здоровых крыс составил 7,0土1,4 ммоль/л. В первые 3-10 дни алкоголизации крысы выпивали по $3,2 \pm 0,7$ мл/100 г веса этанола. К концу 3 недели этот показатель составил 4,9 $\pm 1,1$ мл/100г веса. Потребление этанола достигло максимума к концу 6 недели 6,4 мл/100г. В ходе алкоголизации наблюдалась гипогликемия $3,0 \pm 0,7$ ммоль/л. Результаты наблюдений после введения препаратов приведены в таблице 1 и рис.1 и 2 . Введение Зорекса не снизило количество употребляемого алкоголя, тогда как на начальных этапах употребления Тетурама крысы отказались от этанола. Введение глюкозы способствовало нормализации уровни глюкозы в крови $(6 \pm 1,8$ ммоль/л) и снизило количество выпиваемого этанола. Введение Тетурам + Глюкоза привело к отказу от этанола и устранению

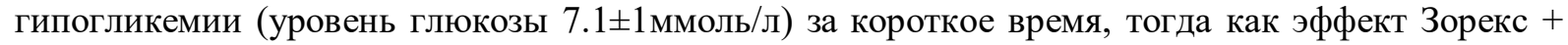
Глюкоза уменьшил количество употребляемого этанола только до $3.5 \pm 1.5$ мл. Введение Зорекса при кетозе имеет кратковременный эффект. После введения глюкозы и Зорекс+глюкозы концентрация кетонов в моче снижается от 1-2 до 0,5 ммоль/л. Тетурам и Глюкоза + Тетурам имеет тот же эффект только время действия последних намного короче (уже на второй неделе до 0,5 ммоль/л)

Таблица 1. Влияние Зорекса и Тетурама на количество употребляемого этанола и на содержание глюкозы в крови.

\begin{tabular}{|c|c|c|c|c|}
\hline № группы & Вещество & $\begin{array}{c}\text { Длительность } \\
\text { в неделях }\end{array}$ & $\begin{array}{c}10 \% \text { этанол на } 100 \\
\text { г массы }\end{array}$ & $\begin{array}{c}\text { Уровень глюкозы } \\
\text { моль/л }\end{array}$ \\
\hline \multirow[t]{3}{*}{ (10 } & \multirow[b]{3}{*}{ Зорекс } & 1 & $5.1 \pm 1.2$ & $3.6 \pm 0.8$ \\
\hline & & 2 & $4.3 \pm 0.8$ & $5.8 \pm 0.9$ \\
\hline & & 3 & $5.1 \pm 0.9$ & $4 \pm 0.9$ \\
\hline \multirow[b]{3}{*}{2} & \multirow[b]{3}{*}{ Глюкоза } & 1 & $4.5 \pm 1.1$ & $6 \pm 1.4$ \\
\hline & & 2 & $3.2 \pm 1.2$ & $6 \pm 1.8$ \\
\hline & & 3 & $2.7 \pm 1$ & $6 \pm 1.8$ \\
\hline \multirow[b]{3}{*}{3} & \multirow[b]{3}{*}{ Глюкоза+Зорекс } & 1 & $5.2 \pm 1.1$ & $6 \pm 1.4$ \\
\hline & & 2 & $3.1 \pm 1.3$ & $6 \pm 1.8$ \\
\hline & & 3 & $3.5 \pm 1.5$ & $7.1 \pm 1.5$ \\
\hline \multirow[b]{3}{*}{4} & \multirow{3}{*}{$\begin{array}{c}0.9 \% \text { раствор } \\
\text { хлорида натрия }\end{array}$} & 1 & $5.5 \pm 0.9$ & $3 \pm 0.7$ \\
\hline & & 2 & $5.5 \pm 1$ & $3 \pm 0.7$ \\
\hline & & 3 & $5.5 \pm 1.2$ & $3.5 \pm 0.8$ \\
\hline \multirow[b]{3}{*}{5} & \multirow[b]{3}{*}{ Тетурам } & 1 & 2,7 & $3 \pm 0.7$ \\
\hline & & 2 & 0 & $3 \pm 0.7$ \\
\hline & & 3 & 0 & $3,5 \pm 0.7$ \\
\hline \multirow[b]{3}{*}{6} & \multirow[b]{3}{*}{ Глюкоза+Тетурам } & 1 & 2,5 & $6 \pm 1$ \\
\hline & & 2 & 0 & $6 \pm 1,2$ \\
\hline & & 3 & 0 & $7.1 \pm 1$ \\
\hline
\end{tabular}

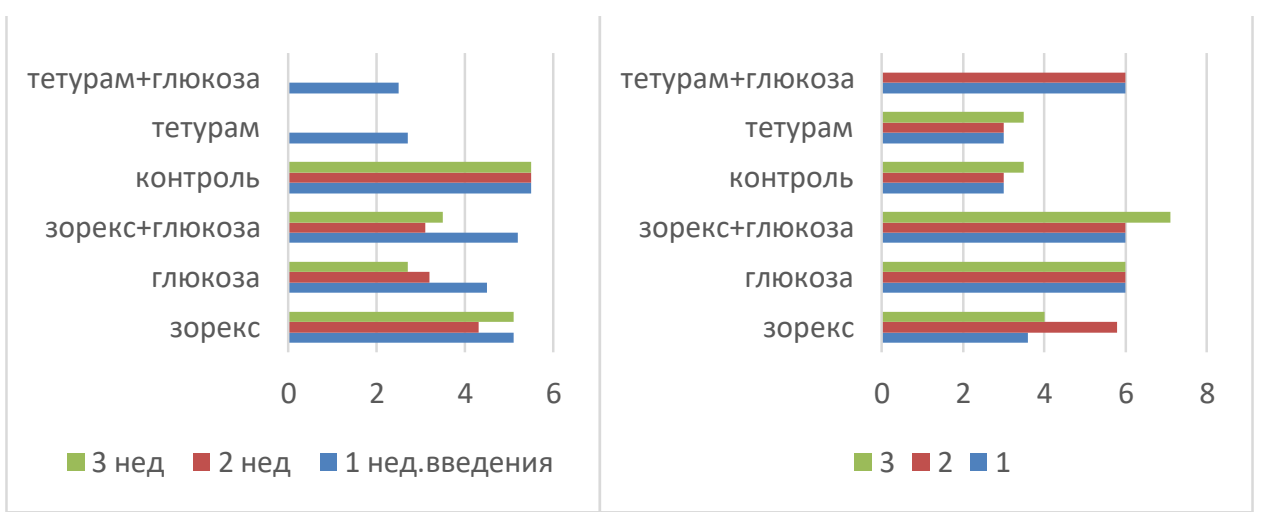

Рис.2. Влияние Зорекса на количество Рис.2. Влияние Тетурама на содержание употребляемого этанола глюкозы в крови 
У всех крыс в ходе алкоголизации наблюдалась кетонурия. Изменения в составе мочи после введения препаратов представлены в таблице 2 и рис.3.

Таблица 2. Влияние Зорекса и Тетурама на содержание кетоновых тел в моче

\begin{tabular}{|c|c|c|c|}
\hline № группы & Вещество & $\begin{array}{c}\text { Длительность в } \\
\text { неделях }\end{array}$ & Концентрация кетонов, ммоль/л \\
\hline \multirow{3}{*}{ (-1) } & \multirow[b]{3}{*}{ Зорекс } & 1 & $1 \pm 0,5$ \\
\hline & & 2 & 1 \\
\hline & & 3 & 1 \\
\hline \multirow[b]{3}{*}{2} & \multirow[b]{3}{*}{ Глюкоза } & 1 & 1 \\
\hline & & 2 & $0,5 \pm 0,3$ \\
\hline & & 3 & 0,5 \\
\hline \multirow[b]{3}{*}{3} & \multirow[b]{3}{*}{ Зорекс +глюкоза } & 1 & 1 \\
\hline & & 2 & $0,5 \pm 0,4$ \\
\hline & & 3 & 0,5 \\
\hline \multirow[b]{3}{*}{4} & \multirow{3}{*}{$\begin{array}{c}0.9 \% \text { p-p хлорида } \\
\text { натрия }\end{array}$} & 1 & $1-2$ \\
\hline & & 2 & $1-2$ \\
\hline & & 3 & $1-2$ \\
\hline \multirow[b]{3}{*}{5} & \multirow[b]{3}{*}{ Тетурам } & 1 & 1 \\
\hline & & 2 & 0,5 \\
\hline & & 3 & 0,5 \\
\hline \multirow[b]{3}{*}{6} & \multirow[b]{3}{*}{ Тетурам+Глюкоза } & 1 & 0,5 \\
\hline & & 2 & $0,4-0,6$ \\
\hline & & 3 & 0,4 \\
\hline
\end{tabular}

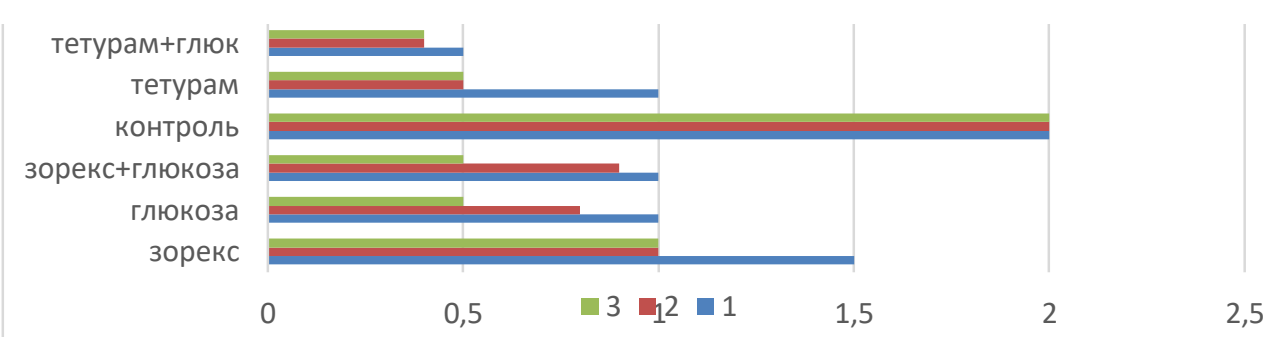

Рис.3. Влияние Зорекса и Тетурама на содержание кетоновых тел в моче

Анализируя данные эксперимента пришли к следующим заключениям:

- потребление этанола сопровождается выраженным кетозом;

- устранение кетоза Зорексом имеет кратковременный эффект и восстанавливается пока животные потребляют этанол;

- введение зорекса не подавляет влечение к этанолу и не устраняет гипогликемию;

- устранение гипогликемии заметно подавляет влечение к этанолу и кетоз;

- после систематического введения глюкозы его концентрация возобновляется до нормальной; снижается;

- после введения Тетурама количество потребляемого этанола экспоненциально

- введение Тетурама ведет к увеличению концентрации ацетальдегида в крови, поэтому дальнейшие превращения до кетоновых тел не происходит.

\section{Выводы:}

1. Зорекс нейтрализует только кетоновые тела, но не устраняет влечение к этанолу. Наоборот лишая мозг от питательного субстрата, он провоцирует организм на употребление алкоголя.

2. Устранение гипогликемии заметно подавляет влечение к этанолу и кетоз.

3. Тетурам с глюкозой ведет к отказу от потребления этанола так же и к устранению гипогликемии, что ускорит процесс перестройки питания мозга на глюкозу. 
4. Значит в клинической практике с помощью Тетурама можно остановить влечение к этанолу, а затем введением глюкозы дополнить процедуру лечения для получения наилучшего результата.

\section{ЛИТЕРАТУРА}

- Avogaro A., Tiego A.// Diabete Metab Rew. - 1993. - Vol. 9. - P. 129-146

- Анохина И. П., Коган Б. М., Маньковская И. В. Общность патогенетических механизмов алкоголизма и наркоманий и пути поиска средств для лечения этих заболеваний // Эксперим. и клин, фармакол., 1990; 53: 4-9.

- Кондрашенко В.Т Алкоголизм Беларусь, Минск ,1983, 288 с.

- Панова Т.И и Бортникова А.К. Роль кетоза в алкогольной зависимости. // Белорусский журнал. Белорусская наука, Минск, 2012 г,114 с

- Попечителов Е.П., Старцев О.А. Аналитические исследования в медицине, биологии и энзимологии. М.: Высшая школа, 2007. - 279 с.

- Пронько П. С., Кузьмич А. Б., Зиматкин С. М. Концентрация ацетальдегида в крови у интактных крыс при алкогольной интоксикации и действии ингибиторов альдегиддегидрогеназы // Вопр. наркологии. -1993. -№3. - С. 40-54. 